\title{
SYSTEM OF BALANCED INDICATORS IN THE ECONOMIC SECURITY OF THE ENTERPRISE
}

\author{
(C) 2020 Tatarovskij Yury Alekseevich \\ Candidate of Economics, Associate Professor \\ Samara State University of Economics \\ E-mail: tatarovsky.yury@yandex.ru
}

Keywords: balanced scorecard, economic security, businesses, financial stability, due diligence, good balance, business process.

The article is devoted to the use of a system of balanced indicators in the implementation of the enterprise's economic security system. The author considers the implementation of the balanced scorecard concept through the prism of the following components: financial component, contractors, personnel, internal business processes. Quantitative indicators were proposed for using each component.

УДК 004, 336

Код РИНЦ 06.00.00

\section{РАЗВИТИЕ ЦИФРОВОЙ ЭКОНОМИКИ В БАНКОВСКОМ СЕКТОРЕ НА ПРИМЕРЕ БЛОКЧЕЙНА}

\author{
() 2020 Тимофеева Арина Юрьевна \\ студент \\ Самарский государственный университет \\ E-mail: arina_tim007@mail.ru
}

Ключевые слова: цифровая экономика, "сквозные" технологии, блокчейн, смарт-контракты, криптовалюта, "Мастерчейн".

Сегодня экономику можно классифицировать как цифровую экономику, так как почти все операции в банковской сфере проводятся онлайн. Именно поэтому в данной статье рассматривается сущность блокчейна и его развитие в российской экономике.

Цифровая экономика так или иначе касается всех сфрер жизни общества. Однако именно банки являются основными проводниками "сквозных" технологий в индустрию финансовых услуг. Создается особая система, которая полностью изменяет функционирование банковского сектора, например, теперь множество операций происходят в online-режиме, что позволяет быстро проводить безналичные платежи. Таким образом данные услуги становятся более доступными для граждан и организаций. Но с появлением технологий, связанных с сетью Интернет, участились случаи виртуального мошенничества, поэтому гарантировать безопасность данных потребителей может блокчейн, 0 котором пойдет речь в данной статье. 
Итак, блокчейном считается такая технология распределенного реестра, где каждый блок содержит набор подтвержденных транзакций (операций, произведенных пользователями сети, например, покупка товара, отправка средств) ${ }^{1}$. То есть в нем записываются данные на всех компьютерах одновременно, поэтому большое количество участников может получить доступ к базе. Как говорилось ранее, любая централизованная система может быть взломана, однако блокчейн не позволяет это сделать, так как он состоит из множества блоков, в которых содержится необходимая информация, и новые блоки несут в себе зашифрованные данные из предыдущих. Именно поэтому попытка взлома будет замечена другими участниками сети и быстро ликвидирована. Также исследуемая цифровая технология работает без посредников. То есть значительно уменьшается риск подделки документов, краже финансовых средств. Это позволяет напрямую обмениваться данными, так как транзакции проверяют непосредственно сами участники сети. Еще одной возможностью недопущения фральсификации документов является серьезный алгоритм шифрования. На основе строгих математических вычислений информация становится неизменной, то есть никто не может изменить произведенную операцию2.

Блокчейн-технология получила широкое распространение не только за рубежом, но и в России. Однако, что касается такой виртуальной валюты как криптовалюта, с которой блокчейн неразрывно связан, то российская экономика пока не использует ее, в отличие от европейских стран (Bank of England выпустил свою валюту RSCoin, в рамках централизованной системы, то есть даннье о транзакциях будут храниться в ЦБ; Deutsche Bundesbank c 2018 года выпускает в качестве законного платежного средства Bitcoin, который приравнивается к евро) и Америки (Bank of America в конце 2019 года признал Bitcoin лучшей инвестицией за последние 10 лет, то есть, если бы в 2010 году мы инвестировали $1 \$$, то в 2019 можно было бы получить примерно 90 000\$) 3 .

На сегодняшний день российская экономика довольно успешно использует блокчейн в банковском секторе. Так, автоматизация процессов сокращает штат сотрудников и тем самым снижает издержки, которые могли бы понести банки при большом количестве подчиненных. По мнению руководителя blockchain-лаборатории Антона Шугая, при использовании данной технологии возможность сократить издержки банков возрастает до 80\%. Быстрая обработка операций позволяет уменьшить документооборот, так как инсормацию по сделкам можно отследить через Интернет, например, при выдаче кредитов или страховых полисов. Как следствие, повышается качество услуг, проводимых без посредников, для конечных потребителей ${ }^{4}$.

Какие именно финансовые организации используют данную цифровую технологию? Рассмотрим несколько примеров. Альфа-Банк и S7 Airlines (авиакомпания международного альянса "oneworld") в 2016 году впервые провели сделку-аккредитив (такая услуга банка, необходимая для проведения крупной сделки) на основе блокчейна, используя Smart contract или смарт-контракты, то есть такой компьютерный алгоритм, который позволяет контролировать и предоставлять информацию о владении чем-либо 5 . Особенностью данной операции являлось применение двух смарт-контрактов (для открытия и закрытия аккредитива), что снизило вероятность возникновения ошибки в коде, увеличило уровень безопасности и стало более прозрачной. Продолжив свое сотрудничество в данной области, авиакомпания затрачивает меньше времени для расчета со своими посредниками. S7 проводит все операции в режиме online, в реальном времени; 
такие действия значительно снижают его дебиторскую задолженность и позволяют Альфа-банку следить за проведенными операциями.

В 2017 году Сбербанк и Федеральная антимонопольная служба (ФАС) России использовали блокчейн при передаче документов. Целью данного эксперимента являлось исследование возможности хранения данных в рамках децентрализованной системы для повышения надежности, скорости и качества их взаимодействия при обмене. Также Сбербанк и "Северсталь" в 2017 провели первую международную аккредитивную сделку6, которая заключалась в том, что от момента подачи документов и до завершения операции участники могли следить за действиями сторон. Стоит отметить, что это было первое решение, проведенное в Восточной Европе ${ }^{7}$. Сегодня Сбербанк с помощью системы Сбербанк Факторинг активно сотрудничает с М.Видео на основе блокчейна. Данная технология, по мнению финансового директора "М.Видео" Екатерины Соколовой, позволяет уменьшить риски потери конфиденциальности информации, так как раньше проверка товара перед проведением платежей проводилась либо по переписке, либо телефонными звонками. Сегодня почти 70\% факторинговых операций ПАО "М.Видео" переведено на систему распределенного реестра8.

Необходимо также отметить Ассоциацию ФинТех (Ассоциация развития финансовых технологий), основанную в 2016 году. Ее целью является создание условий для развития цифровой экономики в России и внедрение новых "сквозных" технологий для обеспечения успешного функционирования банковского сектора. Данная организация позволила создать первую в мире блокчейн платформу "Мастерчейн"9. В его основе лежит принцип открытого блокчейна Ethereum, доработанного специально для российского законодательства. На основе цифровой платформы построена работа с закладными у "Райффайзенбанка". То есть децентрализованная система хранения информации позволяет ускорить и упростить процесс поведения сделок, уменьшить риски отсутствия залога. По факту значительно снижаются расходы участников финансовой сферы и увеличивается уровень стабильности и надежности данных о закладных ${ }^{10}$. После законодательного утверждения электронных закладных (согласно Приказу Минэкономразвития России от 26.04.2018 N 231 "Об утверждении формы электронной закладной") выпуск этих ценных бумаг происходит с помощью услуги SmartDeal, которая предоставляет возможность совершить процесс регистрации в режиме online, после чего документы сразу отправятся в Росреестр ${ }^{11}$. Операция протекания сделки очень простая: так, сотрудник банка вместе с клиентом составляют заявление, подписывают необходимые бумаги о регистрации электронной закладной; данная информация проходит через платформу SmartDeal, где формируется электронная подпись; далее закладная отправляется в Росреестр; там непосредственно формируется весь пакет документов и вскоре можно проводить оплату госпошлины также через SmartDeal.

По данным исследования, проведенного аналитической компанией MINDSMITH, в России очень активно развивается технология блокчейна: в системе финансов, логистике, топливно-энергетическом комплексе. Он позволяет сокращать время проведения операций от нескольких часов до нескольких секунд, бумажный документооборот, то есть исключается риск потери важных документов и допущения в них ошибок, предоставляет прозрачный контроль за всеми операциями. Например, более чем 150 компаний, работающих с блокчейном, могут в ближайшем будущем принести российской экономике около \$25 млрд, большинство банков РФ включается в работу с данной информационной технологией. Так, множество банков уже проводит online-платежи, "АК БАРС" банк, 
Райффазенбанк и другие занимаются токенизацией традиционных финансовых инструментов (то есть на документах используется электронная подпись), Сбербанк, Банк "Открытие", Московский кредитный банк, "АК БАРС" банк и другие занимаются децентрализованным документооборотом ${ }^{12}$.

Можно сделать вывод, что Россия стремится занять одно из лидирующих позиций по использованию данной цифровой технологии. Однако полностью использовать функции блокчейна на территории РФ мы пока не можем, так как в законодательстве нет нормативного регулирования отношений с криптовалютами. Именно поэтому возможно создание крипторубля в ближайшие годы (2020-2021). Такая криптовалюта, во-первых, поможет быстрее обналичивать биткоины в реальные средства.

Во-вторых, крипторубль позволит оплачивать гражданам услуги и товары внутри страны под надзором государства. Данная мера предосторожности позволит снизить риск мошенничества в системе.

B-mретьих, валюта будет иметь достаточно стабильный курс и высокую скорость денежных переводов 13 .

Таким образом, хочется отметить повышающийся интерес различных организаций по отношению к блокчейну. Как отмечалось ранее, он внедряется не только в банках, но и в сфрере производства, малого бизнеса, поэтому распространение данной технологии во всех отраслях экономики будет способствовать большей доступности совершения каких-либо сделок для населения, уменьшению уровня мошенничества и краже данных, а также платежных средств из-за прозрачности проведения операций. Итак, блокчейн это будущее России, которое позволит вывести ее на новый уровень развития.

${ }^{1}$ Сущность понятия "блокчейн" [Электронный ресурc] URL: https://mcs.mail.ru/blog/blokcheyndlya-bankov-otlozhennaya-revolyutsiya-ili-pereotsenennaya-tekhnologiya

2 Функционирование блокчейна [Электронный ресурc] URL: http://bestinvestpro.com/blokchejnchto-eto-ponyatnym-yazykom/

3 Использование блокчейна в Европе и Америке [Электронный ресурc] URL: https://ru.ihodl.com/analytics/2019-12-30/kriptovalyutnyj-rynok-itogi-2019-goda/

4 Примеры использования блокчейна в России [Электронный ресурc] URL: https://ex4.ru/blokchejn/blokchejn-bankov/

5 Понятие смарт-контракта [Электронный ресурc] URL: https://ru.wikipedia.org/wiki/\%D0\%A1\%D0\%BC\%D0\%B0\%D1\%80\%D1\%82-

$\%$ D0\%BA\%D0\%BE\%D0\%BD\%D1\%82\%D1\%80\%D0\%B0\%D0\%BA\%D1\%82

6 Понятие аккредитивной сделки [Электронный ресурc] URL: https://www.sberbank.ru/ru/person/additional/accreditive

7 Международная аккредитивная сделка между Сбербанком и "Северсталью" [Электронный pecypc] URL: https://www.rbc.ru/vo/01/06/2017/593007899a7947c3e135d5f6

8 Сотрудничество Сбербанка и "М.Видео" [Электронный ресурc] URL: https://vc.ru/crypto/21979mvideo-blockchain.

9 "Мастерчейн" - первый юридически чистый блокчейн в России [Электронный ресуpc] URL: http://masterchain.rbc.ru/

10 Изменение работы с закладными, перевод на электронные закладные [Электронный реcypc] URL: https://comnews.ru/content/115056/2018-09-25/rossiyskie-banki-proveli-pervye-ipotechnyesdelki-s-elektronnymi-zakladnymi?utm_source=telegram\&utm_medium=general\&utm_campaign=general

11 Приказ Минэкономразвития России от 26.04.2018 N 231 "Об утверждении формы электронной закладной, формы соглашения о внесении изменений в электронную закладную, требований к заполнению формы электронной закладной, соглашения о внесении изменений в элек- 
тронную закладную, а также требований к их формату" [Электронный ресурс - КонсультантПлюс] URL: http://www.consultant.ru/law/hotdocs/54660.html/

12 Будущее блокчейна в России [Электронный ресурc] URL: https://bits.media/na-rbw-obsudilibudushchee-blokcheyna-v-rossii/

13 Идея создания крипторубля [Электронный ресурc] URL: https://info.finance/obzorkriptovalyut/kriptorubl-nacionalnaya-kriptovalyuta-rossii

\title{
THE DEVELOPMENT OF THE DIGITAL ECONOMY IN THE BANKING SECTOR WITH BLOCKCHAIN
}

\author{
(C) 2020 Timofeeva Arina Yuryevna \\ Student \\ Samara State University of Economics \\ E-mail: arina_tim007@mail.ru
}

Keywords: digital economics, end-to-end technologies, blockchain, smart contract, cryptocurrency, "Masterchain".

Today economics is digital because an increasing number of operations becomes online in the banking sector. It is worth to consider the principle and essence of blockchain and its participation in Russia.

УДК 336.748.12

Код РИНЦ 06.00.00

\section{ЦИФРОВАЯ ИНФЛЯЦИЯ КАК СЛЕДСТВИЕ РАЗВИТИЯ ЦИФРОВОЙ ЭКОНОМИКИ}

\author{
() 2020 Тимофеева Арина Юрьевна* \\ студент \\ Самарский государственный университет \\ E-mail: arina_tim007@mail.ru
}

Ключевые слова: цифровая инфляция, уравнение Фишера, цифровые технологии, антиинфляционный эффрект, интернет-торговля.

С развитием цифрровой экономики появляются сквозные технологии, которые значительно упрощают нам жизнь. Участвуя почти во всех ссрерах экономической отрасли, они оказывают влияние на цены. Поэтому данная статья посвящена цифровой инфляции как феномену, возникшем в современном мире.

Началом развития цифровой экономики можно считать конец 20в. Сейчас данная сфера представляет собой одну из самых развивающихся отраслей современной экономики. Так,

* Научный руководитель - Лунин Игорь Анатольевич, старший преподаватель. 